\title{
Topical colchicine selection of keratinocytes transduced with the multidrug resistance gene (MDR1) can sustain and enhance transgene expression in vivo
}

\author{
W. Pfützner*†, A. Terunuma*, C. L. Tock*, E. K. Snead*, T. M. Kolodka, M. M. Gottesman§, L. Taichman, \\ and J. C. Vogel*ף \\ *Dermatology Branch, Building 10/Room 12N260, National Cancer Institute, National Institutes of Health, 10 Center Drive, MSC 1908, Bethesda, MD \\ 20892-1908; §Laboratory of Cell Biology, Building 37/Room 1A09, National Cancer Institute, National Institutes of Health, 37 Convent Drive, \\ MSC 4254, Bethesda, MD 20892-4254; and ₹Department of Oral Biology and Pathology, School of Dental Medicine, \\ State University of New York, Stony Brook, NY 11794-8702
}

Edited by Ira Pastan, National Institutes of Health, Bethesda, MD, and approved June 27, 2002 (received for review April 25, 2002)

For skin gene therapy, achieving prolonged high-level gene expression in a significant percentage of keratinocytes (KC) is difficult because we cannot selectively target KC stem cells. We now demonstrate that topical colchicine treatment can be used to select, in vivo, $\mathrm{KC}$ progenitor cells transduced with the multidrug resistance gene (MDR1). When human skin equivalents containing MDR1-transduced KC were grafted onto immunocompromised mice, topical colchicine treatments significantly increased (7-fold) the percentage of KC expressing MDR1, compared to vehicle-treated controls, for up to $24 \mathrm{wk}$. Topical colchicine treatment also significantly enhanced the amount of MDR1 protein expressed in individual KC. Furthermore, quantitative real-time PCR analysis of MDR1 transgene copy number demonstrates that topical colchicine treatment selects and enriches for KC progenitor cells in the skin that contain and express MDR1. For clinical skin gene therapy applications, this in vivo selection approach promises to enhance both the duration and expression level of a desired therapeutic gene in $\mathrm{KC}$, by linking its expression to the MDR1 selectable marker gene.

A chieving persistent transgene expression in a high percentage of targeted cells remains an important goal to establish successful clinical applications of gene therapy. Although retroviral vectors are able to stably integrate into the host genome, in vivo gene expression is often lost or diminished over time, as has been shown in skin and other tissues (1-3). Possible reasons include a failure to efficiently target tissue progenitor cells (stem cells) and/or the gene silencing of the integrated retroviral vector $(4,5)$.

One approach to ensure sustained, enhanced expression of the therapeutic gene in a high percentage of target tissue cells would be to transduce cells with a bicistronic vector containing the therapeutic gene linked to a selectable marker gene. During in vivo selection with a cytotoxic drug, cells protected by selectable gene expression would have a proliferative advantage, enriching for transduced progenitor cells and cells with increased transgene expression. The feasibility of this concept has been examined by transducing hematopoietic cells with different selectable marker genes (6-12). However, selection often yielded relatively small increases in the percentage of transduced cells, depending on the initial transduction efficiency. Additionally, high doses of the appropriate cytotoxic drug were required, resulting in systemic toxicity, and occasionally, death of the treated animals $(6,12)$.

The skin is a very compelling organ for gene therapy (13-15). Keratinocytes $(\mathrm{KC})$, the major cell type of the epidermis, are readily accessible and can be expanded by using standard cell culture techniques. High transduction efficiency of $\mathrm{KC}$ with retroviral vectors can be achieved during ex vivo culture, and skin equivalents can be created with genetically modified $\mathrm{KC}$ and then grafted to establish a functional, durable epidermis $(16,17)$. Bioengineered skin expressing a therapeutic gene can be used to treat an increasing number of genetically inherited skin disorders $(18,19)$ and also may be used to produce biologically active molecules for the treatment of systemic diseases $(3,20,21)$. Although gene expression from retroviral vectors has been detected for prolonged periods in grafted $\mathrm{KC}(3,17,22,23)$, the level of in vivo transgene expression was frequently low or declined over time when assessed quantitatively $(1-3,21,24)$.

Recently, we described an in vitro skin model where $\mathrm{KC}$ transduced with the multidrug resistance gene (MDRl) were enriched to almost $100 \%$ by selection with colchicine (25). The human MDR1 gene encodes a transmembrane efflux transporter (P-glycoprotein) for a wide variety of cytotoxic drugs $(26,27)$ and is endogenously expressed in several human tissues associated with secretory or barrier functions but not in $\mathrm{KC}(28,29)$. Because the MDRl gene encodes a human protein, it should not elicit an immune response, unlike many other selectable marker genes that encode foreign proteins. A unique advantage of the skin is that topically applied cytotoxic drugs will be less likely to cause systemic toxicity. Colchicine, an antimitotic agent that binds to tubulin and blocks cell division, is a good candidate for topical selection because it should inhibit proliferation of normal $\mathrm{KC}$, while allowing $\mathrm{KC}$ expressing MDR1 P-glycoprotein $(\mathrm{MDR}+\mathrm{KC})$ to proliferate and repopulate the epidermis.

In this in vivo study, we report that topical colchicine selection of $\mathrm{MDR}+\mathrm{KC}$ grafts can expand the population of $\mathrm{KC}$ expressing MDR1 P-glycoprotein (MDR $+\mathrm{KC})$, enhance the level of $\mathrm{P}$ glycoprotein expression without interfering with the biological integrity of the skin, and select for MDR $+\mathrm{KC}$ progenitor cells.

\section{Methods}

Submerged Cell Culture and Transduction. Primary human KC and fibroblasts obtained from neonatal foreskin by enzymatic digestion were grown in serum-free medium plus supplements and DMEM/ $10 \%$ FBS, respectively (GIBCO/BRL). Transduction of both KC and fibroblasts was performed by incubation of first passage cells with the retroviral vector $\mathrm{pHaMDR} 1 / \mathrm{A}(30)$ at a titer of $5 \times 10^{5}$ to $1 \times 10^{6}$ colony-forming units/ml (multiplicity of infection of $1-2$ ) together with Polybrene $(8 \mu \mathrm{g} / \mathrm{ml})$.

Organotypic Raft Culture and Grafting Method. Organotypic raft cultures constructed by established methods (31) were grafted on 4- to 5-wk-old NIH male Swiss $n u / n u$ mice (Taconic Farms),

This paper was submitted directly (Track II) to the PNAS office.

Abbreviations: KC, keratinocytes; hKC, human KC; FB, fibroblasts; FACS, fluorescenceactivated cell sorter.

†Present address: Dermatology Clinic, Ludwig Maximilians University of Munich, 80337 Munich, Germany.

กTo whom reprint requests should be addressed. E-mail: jonvogel@mail.nih.gov. 
housed, and used in accordance with institutional guidelines. Grafts were placed on the muscle fascia in correct anatomical orientation, covered with sterile Vaseline gauze (Sherwood Medical Industries, St. Louis), and secured with a 3/4-inch $\times 3$-inch tape dressing (Baxter Diagnostics, McGaw Park, IL). The dressing was changed at $1 \mathrm{wk}$ and removed after $2 \mathrm{wk}$.

Topical Colchicine Treatment. Colchicine (Sigma) solution (0-600 $\mathrm{mg}$ dissolved in DMSO and subsequently diluted 1:100 with distilled de-ionized water) was mixed with Velvachol cream (Healthpoint, San Antonio, TX) to obtain final dosages of $0-500 \mu \mathrm{g} / \mathrm{g}$ of cream. The colchicine cream was prepared fresh every $8 \mathrm{wk}$ and stored in aluminum tubes. After topical application, the cream was covered with a 3/4-inch $\times 3$-inch tape dressing (Baxter Diagnostics) to enhance the drug penetration and prevent mice from removing the cream. For topical selection, colchicine or vehicle control (Velvachol) cream was applied onto $M D R$-transduced human grafts, two to three times per week, starting 4-5 wk after grafting until grafts were harvested.

Histology. Mice were killed by neck dislocation, and grafts were excised and halved in neutral buffered $10 \%$ formalin (Sigma) for histologic analysis and flow cytometry or PCR analysis. Fixed and paraffin-embedded tissues were stained either with hematoxylin and eosin or with antibodies against human MDR1 P-glycoprotein (C219; Signet Laboratories, Dedham, MA), human involucrin (MEDCLA130; Accurate Scientific, Westbury, NY), or appropriate isotype controls. Staining was performed with the Vectastain Universal ABC-AP kit and Vector Red Alkaline Phosphatase Substrate kit I according to the protocols provided by the manufacturer (Vector Laboratories). For detection of MDR1 expression, tissue sections were also incubated in the antigen-unmasking agent Retrieve-All (Signet Laboratories). Counterstaining was performed by brief exposure to aqueous hematoxylin (Biomedia, Foster City, CA).

Flow Cytometry Analysis. Epidermal KC suspensions obtained from cell culture monolayers or from epidermal sheets harvested from grafts by enzymatic treatment were preincubated with saturating concentrations of anti-Fcy III/IIR (PharMingen) and then serially incubated with saturating concentrations of mouse anti-MDR mAb MRK16 (Kamiya, Seattle), goat anti-mouse secondary Ab conjugated to FITC (BioSource International, Camarillo, CA), and anti-human HLA-A, -B, -C mAb conjugated to R-phycoerythrin (PharMingen). Isotype controls included IgG2a (Becton Dickinson) and R-phycoerythrin-conjugated IgG1 (PharMingen) mAb. Stained cells were analyzed by using a FACScan flow cytometer equipped with CELLQUEST software (Becton Dickinson). Propidium iodide (Sigma)-permeable (nonviable) cells were excluded from the analyses.

To determine MDRl gene function in transduced $\mathrm{KC}$, flow cytometry analysis of monolayers loaded with $200 \mathrm{ng} / \mathrm{ml}$ rhodamine-123 dye (Sigma; $20 \mathrm{~min}$ ), washed, and incubated with or without $1.5 \mu \mathrm{M}$ MDR-reversing agent cyclosporin A (Sigma; $2 \mathrm{~h}$ ) was performed.

Quantitative Real-Time PCR. By using a DNeasy tissue collection kit (Qiagen), DNA samples were obtained either from epidermal sheets of harvested grafts or from first-passage nontransduced and transduced [ $40 \%$ MDR expression by fluorescence-activated cell sorter (FACS) analysis] KC serving as a negative and positive control, respectively. Specific primers and probes were generated for both MDR1 (from pHaMDR1/A) and human hematopoietic cell kinase 1 (HCK) (sequences available by request) (GIBCO/ BRL; Applied Biosystems), and amplification conditions for both templates were optimized to produce a single PCR product for each reaction. Real-time PCR was performed on an Applied Biosystems PRISM sequence detector and software version 1.7. Amplification mixtures contained $25 \mu \mathrm{l}$ of Taqman Universal PCR master mix (Applied Biosystems), $300 \mu \mathrm{M}$ each primer, $250 \mathrm{nM}$ probe, $25 \mathrm{ng}$ of DNA template, and PCR-grade water to a volume of $50 \mu \mathrm{l}$. PCR-cycling conditions were 40 cycles $\left(50^{\circ} \mathrm{C}\right.$ for $2 \mathrm{~min} / 95^{\circ} \mathrm{C}$ for 10 $\mathrm{min} / 60^{\circ} \mathrm{C}$ for $\left.1 \mathrm{~min}\right)$. All PCRs were performed in triplicate and repeated on a subsequent day with new master mix. In addition, nontemplate controls were performed in parallel. Relative gene copy number was determined by using the following equation: gene copy number $=2^{(\Delta \Delta \mathrm{Ct})}$ with $\Delta \Delta \mathrm{Ct}=\left[\Delta \mathrm{Ct}_{\mathrm{HCK}}\right.$ (human keratinocyte) $-\Delta \mathrm{Ct}_{\mathrm{MDR}}($ human keratinocyte $\left.)\right]-\left[\Delta \mathrm{Ct}_{\mathrm{HCK}}(\right.$ transduced keratinocyte) $-\Delta \mathrm{Ct}_{\mathrm{MDR}}$ (transduced keratinocyte)].

Statistical Analysis. Statistical analysis was performed by using an exact Wilcoxon rank sum test to make comparisons between the different groups. The Hochberg method was used to adjust the $P$ values among the primary comparisons (comparison of the percentages of MDR $+\mathrm{KC}$ measured by flow cytometry and the number of $M D R$ genes determined by quantitative real-time PCR analysis). No adjustment was made on the secondary group (MDR protein expression in human $\mathrm{KC}$ measured as mean fluorescence intensity by flow cytometry analysis). $\mathrm{Ct}$ is the cycle number when the amplified PCR product reaches a fixed threshold, whereas $\Delta \Delta \mathrm{Ct}$ is the difference in threshold cycles for two cell types.

\section{Results}

Topical Colchicine Blocks KC Mitosis Without Unwanted Cytotoxic Effects. Because our goal is to use topical selective pressure to increase both the percentage of human $\mathrm{KC}$ expressing human MDR1 P-glycoprotein (MDR+KC) and the average level of MDR1 expression in each $\mathrm{KC}$, we first needed to determine whether colchicine is an effective selective agent against human $\mathrm{KC}$ not transduced with MDRI (hKC). Titrated doses of colchicine cream $(0-500 \mu \mathrm{g} / \mathrm{g}$ of cream) were applied for a period of up to 4 wk (three times per week) onto nude mouse skin and hKC grafted onto nude mice (Fig. 1). Histological analysis showed that in mouse skin, moderate colchicine doses of $100 \mu \mathrm{g} / \mathrm{g}$ led to a marked epidermal acanthosis and an increase of $\mathrm{KC}$ blocked in mitosis without disrupting the epidermal integrity when compared with vehicle control. With $200 \mu \mathrm{g} / \mathrm{g}$ colchicine cream, similar histological features were observed with a further increase of $\mathrm{KC}$ blocked in mitosis (450/1,000 basal cells vs. 15/1,000 basal cells in vehicle control) (Fig. $1 A$ and $B$ ). In addition, a dermal inflammatory infiltrate suggested either increased uptake of colchicine into the dermis or the release of chemotactic pro-inflammatory factors from affected KC (Fig. 1B). High colchicine doses of $500 \mu \mathrm{g} / \mathrm{g}$ caused abundant cell necrosis and total disruption of the epidermal architecture finally leading to ulceration (Fig. 1C).

Analysis of hKC grafts showed that colchicine doses of $200 \mu \mathrm{g} / \mathrm{g}$ also resulted in an increased number of $\mathrm{KC}$ blocked in mitosis compared with vehicle control grafts $(66 / 1,000$ basal cells vs. $8 / 1,000$ basal cells in vehicle control) with moderate disruption of the epidermal architecture but no widespread $\mathrm{KC}$ necrosis (Fig. $1 D)$. The effect of higher colchicine doses $(500 \mu \mathrm{g} / \mathrm{g})$ on hKC grafts could not be assessed because these higher doses had cytotoxic effects on the more sensitive mouse skin surrounding the human grafts. No MDRl expression was present as determined either by immunohistostaining of graft sections or by flow cytometry (FACS) of epidermal cell suspensions taken from these grafts (data not shown), demonstrating that colchicine did not induce unwanted endogenous MDRl expression in $\mathrm{hKC}$.

Topical Application of Colchicine Increases the Percentage of MDR+KC in a Dose-Dependent Manner. We used an ex vivo grafting model to assess the ability of topical colchicine selection to increase the percentage of $\mathrm{MDR}+\mathrm{KC}$ per graft and increase the average level of MDR1 expression per KC. To best assess the selective effects of colchicine, we constructed skin rafts that initially contained $\approx 50 \% \mathrm{MDR}+\mathrm{KC}$ before grafting. FACS analysis with the anti-MDR1 mAb MRK16 confirmed an initial transduction efficiency of $48 \%$ for $\mathrm{KC}$ and $50 \%$ for fibroblasts used to establish skin rafts and also confirmed functional $M D R 1$ expression by demon- 
A

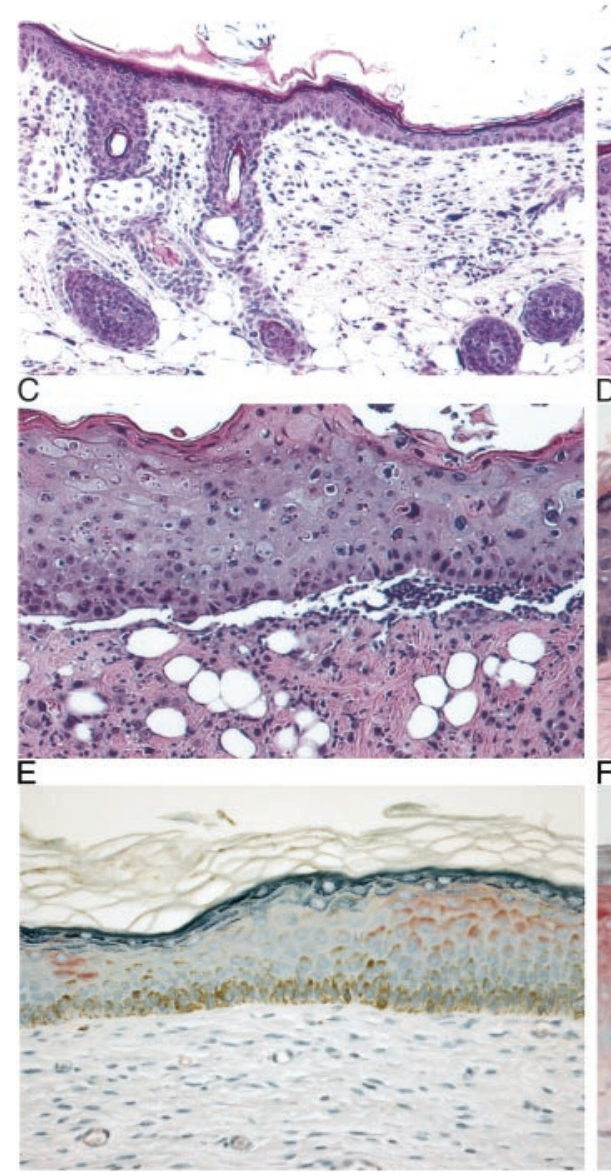

B
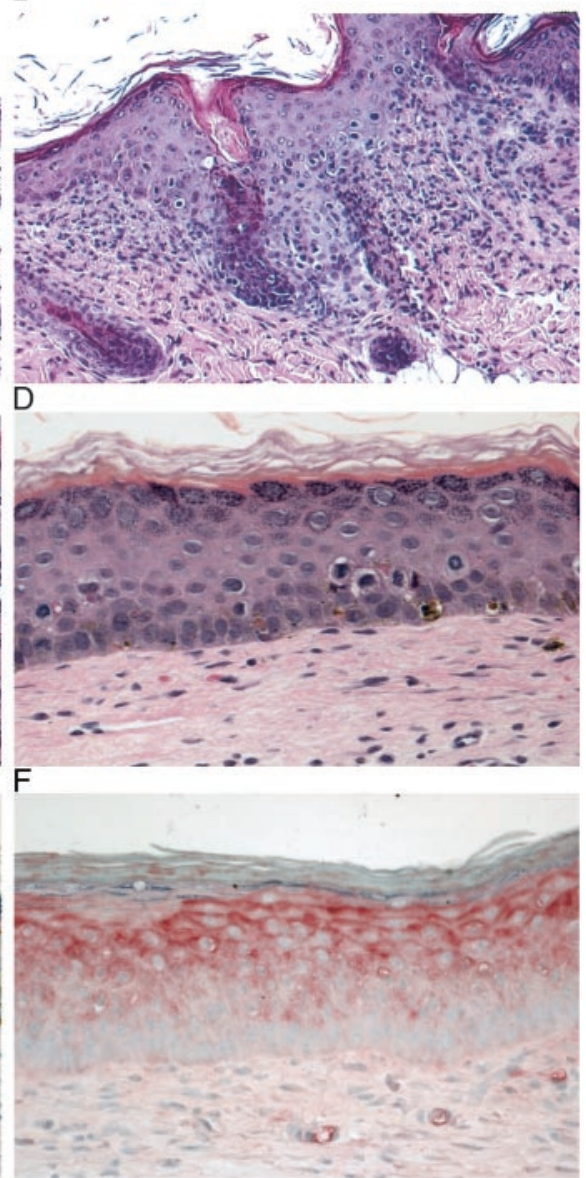

Fig. 1. ( $A-D)$ Topical titration of colchicine treatment demonstrates dose-dependent effects on mouse and human skin (2 wk). Shown are hematoxylin/eosin staining of mouse skin treated with vehicle control cream $(\times 20)(A)$; colchicine $(200 \mu \mathrm{g} / \mathrm{g})$ treatment with increased numbers of $\mathrm{KC}$ blocked in mitosis $(\times 20)(B)$; and colchicine $(500 \mu \mathrm{g} / \mathrm{g})$ treatment with cellular necrosis, severe disruption of the epidermal architecture, and ulceration $(\times 20)(C)$. (D) Hematoxylin/eosin staining of human skin grafts treated with colchicine $(200 \mu \mathrm{g} / \mathrm{g})$ demonstrating $\mathrm{KC}$ blocked in mitosis but no disruption of the epidermal architecture $(\times 40)$. $(E$ and $F)$ Immunohistostaining (alkaline phosphatase) for MDR1 (P-glycoprotein) expression in MDR+KC grafts $(\times 40)$. (E) No colchicine treatment, 4 wk after grafting. $(F)$ colchicine treatment (200 $\mu \mathrm{g} / \mathrm{g}), 7 \mathrm{wk}$ after grafting.

strating that transduced cells could extrude the fluorescent dye rhodamine-123 (data not shown).

The histology of the MDR + KC grafts not treated with colchicine demonstrated a mature, well-differentiated epidermis that contained patches of $\mathrm{MDR}+\mathrm{KC}$ detected by immunohistostaining at 4 wk after grafting and was positive for the human differentiation marker involucrin (Fig. $1 E$ and data not shown). The percentage of $\mathrm{MDR}+\mathrm{KC}$ in the grafts was quantitatively assessed by FACS at different time points after grafting. At 2 and 4 wk after grafting, epidermal cell suspensions generated from the grafts contained $34 \pm 5 \%(n=8)$ and $24 \pm 11 \%(n=7)$ MDR $+\mathrm{KC}$, respectively, demonstrating a progressive decline from the initial $48 \%$ $\mathrm{MDR}+\mathrm{KC}$.

We next used FACS to assess the effects of topical colchicine (100 or $200 \mu \mathrm{g} / \mathrm{g}$ administered three times per week) on the percentage of $\mathrm{MDR}+\mathrm{KC}$. At $7 \mathrm{wk}$, colchicine treatment increased the percentage of MDR $+\mathrm{KC}$ in grafts to $41 \pm 24 \%(n=7)$ and $58 \pm 22 \%$ $(n=6)$ with $100 \mu \mathrm{g} / \mathrm{g}$ and $200 \mu \mathrm{g} / \mathrm{g}$, respectively, whereas grafts treated with vehicle control contained only $20 \pm 9 \%(n=6)$ $\mathrm{MDR}+\mathrm{KC}$ (Fig. $2 A$ and $B$ ). However, only the higher colchicine dose $(200 \mu \mathrm{g} / \mathrm{g})$ significantly increased the MDR $+\mathrm{KC}$ percentage (Fig. $2 B, P=0.008$ ). The epidermis of the colchicine-treated $\mathrm{MDR}+\mathrm{KC}$ grafts demonstrated normal KC proliferation, differentiation, and stratification and contained significantly more $\mathrm{MDR}+\mathrm{KC}$ compared to control grafts (Fig. $1 E$ and $F$ ). $\mathrm{MDR}+\mathrm{KC}$ were usually present as patches or large accumulations on histology sections (Fig. $1 E$, right side and Fig. $1 F$ ), especially in the colchicine-treated grafts, although columns of $\mathrm{MDR}+\mathrm{KC}$ that may represent distinct proliferative units were occasionally seen (Fig. $1 E$, left side). Also, the $\mathrm{MDR}+\mathrm{KC}$ grafts did not have increased numbers of mitotic figures or dyskeratotic cells during colchicine treatment ( $7 \mathrm{wk}$ and later time points) compared with MDR $+\mathrm{KC}$ grafts treated with vehicle control cream, suggesting protection from the antimitotic properties of colchicine. These data demonstrated that MDR $+\mathrm{KC}$ can be selected in vivo by topical colchicine application in a dose-dependent manner with doses of $200 \mu \mathrm{g} / \mathrm{g}$ leading to a significant increase of MDR $+\mathrm{KC}$.

Topical Colchicine Selection Results in Sustained, High-Level Transgene Expression and Percentages of MDR +KC. The epidermis is a highly proliferative tissue with a turnover cycle of $\approx 21 \mathrm{~d}$ in humans $(32,33)[\approx 7 \mathrm{~d}$ in mice (34)], and a significant percentage of KC stem cells must carry the transgene to ensure a sustained high level of gene expression. We assessed the effects of either topical colchicine cream $(200 \mu \mathrm{g} / \mathrm{g}$, three times per week) or vehicle control on $\mathrm{MDR}+\mathrm{KC}$ grafts when harvested at 9 and 15 wk after grafting, representing $\approx 3$ and 5 epidermal turnovers, respectively. At 9 wk, FACS analysis of grafts topically treated with colchicine contained $50 \pm 26 \%(n=8) \mathrm{MDR}+\mathrm{KC}($ median $=40.5 \%)$, whereas the percentage of $\mathrm{MDR}+\mathrm{KC}$ in vehicle control grafts declined to $13 \pm$ 
A

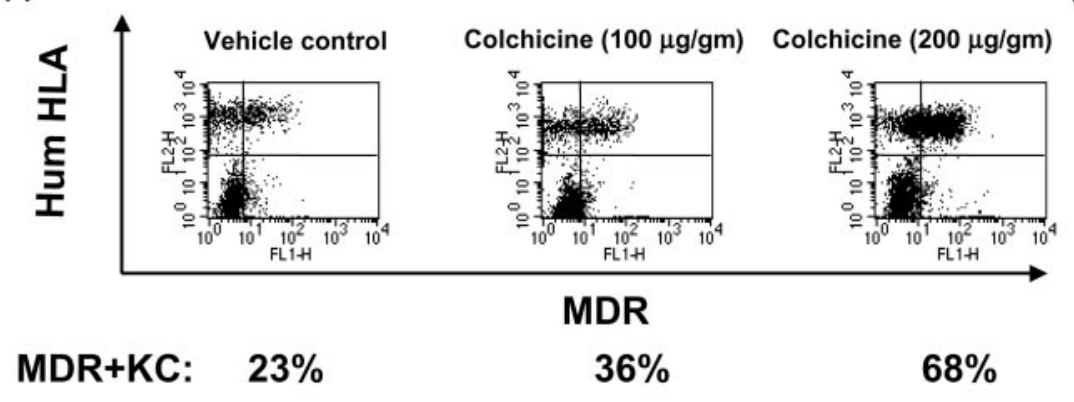

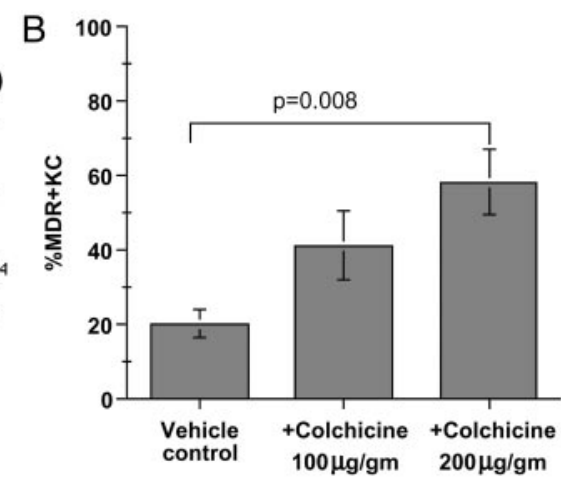

Fig. 2. Dose titration of colchicine treatment on percentage of MDR $+K C$ in grafts. $(A)$ Representative FACS examples of human MDR $+K C$ (right upper quadrant) expressing human HLA antigen (FL2) and MDR1 (FL1), 7 wk after grafting. (B) Average percentage of MDR+KC in grafts treated with different colchicine doses, at week 7.

$5 \%(n=6 ; P=0.002)($ median $=10 \%)($ Fig. $3 A$, Table 1$)$. At 15 wk after grafting, colchicine-treated grafts contained $44 \pm 15 \%$ $(n=8) \mathrm{MDR}+\mathrm{KC}($ median $=45.5 \%)$ whereas the percentage of $\mathrm{MDR}+\mathrm{KC}$ in vehicle control grafts continued to decline to $7 \pm 4 \%$ $(n=7)(P<0.0001)($ median $=8 \%)$, a 7-fold difference (Fig. $3 A$, Table 1). Immunohistostaining confirmed the FACS data with up to $50 \% \mathrm{MDR}+\mathrm{KC}$ in colchicine-treated grafts and much smaller percentages of MDR $+\mathrm{KC}$ in control grafts (Fig. $1 F$ and data not shown). Interestingly, colchicine treatment also increased the amount of MDR1 transgene expressed per MDR + KC compared with vehicle control (Fig. 3B, Table 1). The mean fluorescence intensity of MDR1 expression by FACS analysis was $16 \pm 3(n=8)$ for colchicine-treated grafts compared with $11 \pm 2(n=7)(P=$ $0.006)$ for vehicle control. In summary, topical colchicine treatment promotes selection of MDR $+\mathrm{KC}$ with enhanced transgene expression levels. The demonstration of significantly increased percentages of human $\mathrm{MDR}+\mathrm{KC}$ in colchicine-treated grafts for up to 15 wk (five epidermal turn-over cycles) compared to declining percentages in vehicle control grafts strongly suggests that colchicine selection resulted in enrichment of $\mathrm{MDR}+\mathrm{KC}$ progenitor cells.

We also demonstrated the ability of colchicine to select for increased percentages of $\mathrm{MDR}+\mathrm{KC}$ even when colchicine treatment was initiated at much later times after grafting. Two $\mathrm{MDR}+\mathrm{KC}$ grafts treated with vehicle control cream for $12 \mathrm{wk}$ (a time when control grafts would be expected to average between $7 \%$ and $13 \% \mathrm{MDR}+\mathrm{KC}$ ) were switched to colchicine treatment (200 $\mu \mathrm{g} / \mathrm{g}, 2$ times per week) for another $12 \mathrm{wk}$ (24 wk or 6 mo after grafting). After this selection, FACS analysis revealed elevated percentages of MDR $+\mathrm{KC}$ in these grafts, with $34 \%$ and $35 \%$ of human $\mathrm{KC}$ showing MDR1 expression (data not shown). Thus, 24 wk after grafting (eight epidermal turn-overs), colchicine selection initiated when only a low percentage of $\mathrm{MDR}+\mathrm{KC}$ are present is able to substantially increase the number of MDR $+\mathrm{KC}$.

MDR1-Expressing Fibroblasts (FB) in the MDR+KC Grafts Are Important for Successful Selection. Dermal FB provide necessary stimulatory factors that support $\mathrm{KC}$ epithelialization, and during colchicine selection the presence of $M D R 1$-expressing $\mathrm{FB}(\mathrm{MDR}+\mathrm{FB})$ in the dermis of $\mathrm{MDR}+\mathrm{KC}$ grafts may be important. To determine the effects on MDR $+\mathrm{KC}$ growth, MDR+KC grafts were constructed with MDR $+\mathrm{FB}$ (50\% transduction efficiency by FACS) and compared to grafts containing human $\mathrm{FB}$ not expressing $M D R 1,9$ wk after grafting. Although the percentage of $\mathrm{MDR}+\mathrm{KC}$ increased to $80 \pm 12 \%(n=7)$ in colchicine-treated grafts containing human $\mathrm{FB}$, compared to $50 \pm 26 \%,(n=8) \mathrm{MDR}+\mathrm{KC}$ in grafts containing MDR $+\mathrm{FB}$, frequent ulcerations and significantly fewer hKC were present in the grafts containing human $\mathrm{FB}$ $(19 \pm 16 \% ; n=7)$ compared with grafts with MDR +FB (46 \pm $22 \% ; n=8$ ) (Fig. $3 C$ ). Consequently, the grafts constructed with $\mathrm{MDR}+\mathrm{FB}$ in the dermis contain greater total numbers of $\mathrm{MDR}+\mathrm{KC}$ and have superior structural integrity (Fig. 3C).

Topical Colchicine Selection of MDR1-Transduced Human KC Significantly Increases Transgene Copy Numbers in Grafts. One important observation to explain is why colchicine-treated grafts maintain $\approx 50 \% \mathrm{MDR}+\mathrm{KC}$ whereas the percentage of $\mathrm{MDR}+\mathrm{KC}$ in vehicle control grafts progressively declines to $\approx 7 \%$ at later time points. MDR1 expression may be increased because colchicine selection increases the percentage of $\mathrm{KC}$ progenitor cells containing the $M D R 1$ gene. Alternatively, colchicine selection may increase $M D R 1$ expression by preventing $M D R 1$ transgene silencing $(4,5)$. The best way to distinguish between these two mechanisms is to determine

Table 1. Percentage of MDR+KC and the level of MDR1 protein expression in individual MDR+KC, at 9 wk and 15 wk after grafting

\begin{tabular}{|c|c|c|c|c|c|c|}
\hline \multicolumn{3}{|c|}{ Week 9 grafts } & \multicolumn{4}{|c|}{ Week 15 grafts } \\
\hline & Vehicle control $(n=6)$ & + Colchicine $(n=8)$ & \multicolumn{2}{|c|}{ Vehicle control $(n=7)$} & \multicolumn{2}{|c|}{+ Colchicine $(n=8)$} \\
\hline & $\mathrm{MDR}+\mathrm{KC}, \%$ & $\mathrm{MDR}+\mathrm{KC}, \%$ & $\mathrm{MDR}+\mathrm{KC}, \%$ & $\begin{array}{c}\text { MDR expression, } \\
\text { MFI }\end{array}$ & $\mathrm{MDR}+\mathrm{KC}, \%$ & $\begin{array}{c}\text { MDR expression, } \\
\text { MFI }\end{array}$ \\
\hline & 10 & 42 & 10 & 9.42 & 66 & 19.45 \\
\hline & 9 & 18 & 3 & 10.76 & 44 & 14.91 \\
\hline & 18 & 67 & 5 & 10.28 & 25 & 13.42 \\
\hline & 10 & 35 & 1 & 10.03 & 47 & 15.72 \\
\hline & 21 & 97 & 8 & 11.28 & 35 & 12.28 \\
\hline & 8 & 67 & 10 & 13.13 & 24 & 14.24 \\
\hline & & 31 & 10 & 15.13 & 60 & 20.14 \\
\hline & & 39 & & & 52 & 17.14 \\
\hline Mean \pm SD & $13 \pm 5$ & $50 \pm 26$ & $7 \pm 4$ & $11 \pm 2$ & $44 \pm 15$ & $16 \pm 3$ \\
\hline
\end{tabular}

MFI, mean fluorescence intensity. 
A
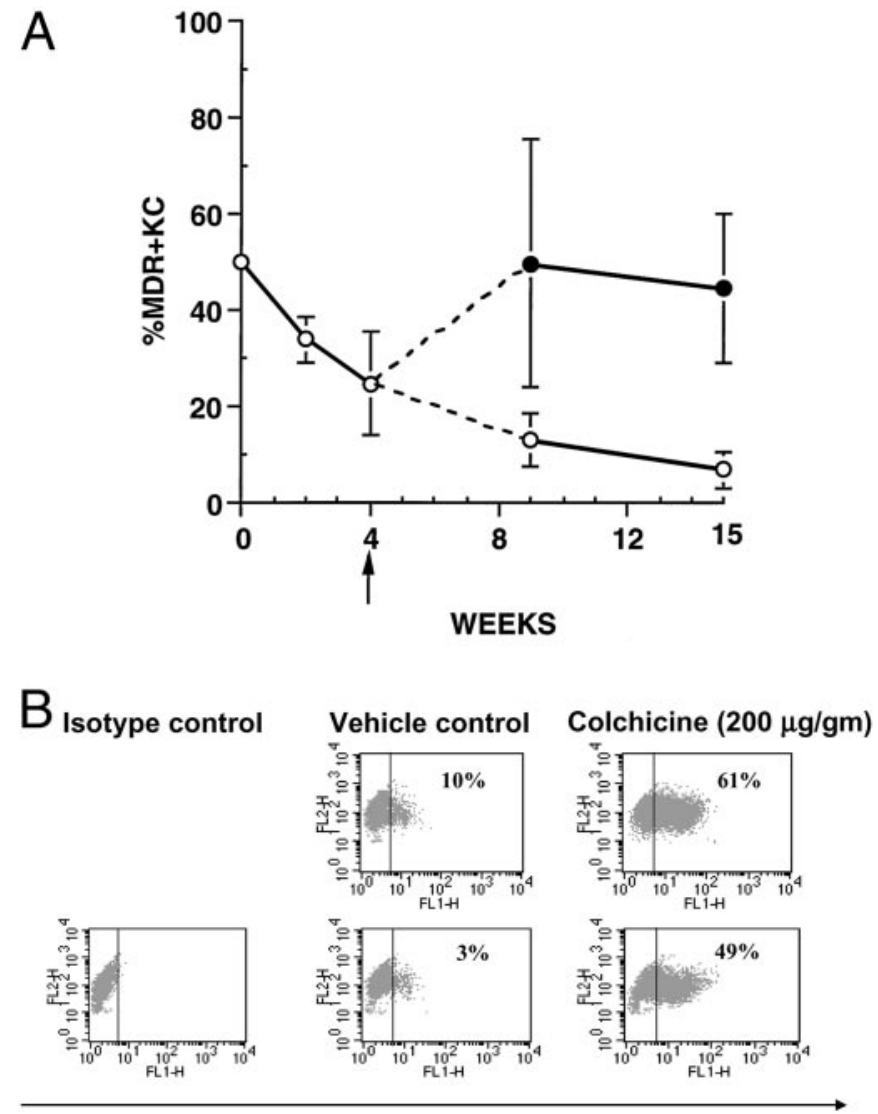

MDR
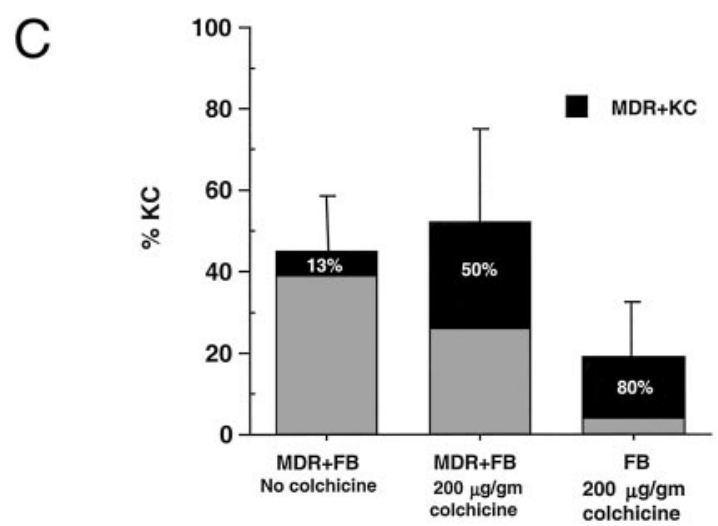

Fig. 3. Colchicine treatment increases percentage of $M D R+K C$ and MDR1 expression level over time. ( $A$ ) Percentage of MDR + KC in grafts (by FACS analysis) at various time points after grafting, either with colchicine treatment starting at week 4 (upper line) or without colchicine treatment (lower line). (B) Representative FACS analysis of grafts treated with vehicle or colchicine at 15 wk; FL1 channel demonstrates level of MDR1 expression. (C) The effect of MDR1expressing fibroblasts or MDR-negative fibroblasts on the percentage of hKC and percentage of MDR $+\mathrm{KC}$ in grafts treated with either vehicle or colchicine, $9 \mathrm{wk}$ after grafting.

how many $\mathrm{KC}$ in the grafts contain the $M D R 1$ gene and correlate this to the percentage of $\mathrm{MDR}+\mathrm{KC}$ ( $\mathrm{KC}$ actually expressing P-glycoprotein). In the first mechanism, the percentage of grafted KC containing the $M D R 1$ gene will be equivalent to the percentage of $\mathrm{MDR}+\mathrm{KC}$ in both colchicine and vehicle-treated grafts. However, in the second mechanism, the percentage of $\mathrm{KC}$ containing the $M D R 1$ gene would be greater than the percentage $\mathrm{MDR}+\mathrm{KC}$ in vehicle control grafts.

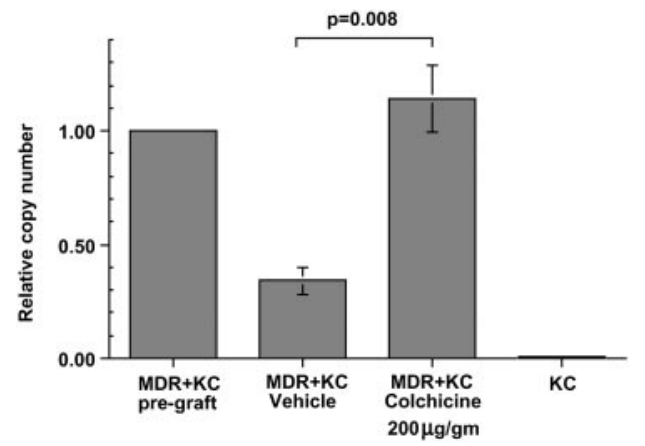

Fig. 4. Quantitative $P C R$ determination of $M D R 1$ gene copy number in $\mathrm{MDR}+\mathrm{KC}$ grafts. The relative MDR1 copy number was determined by quantitative real-time $P C R$ in MDR+KC grafts just before grafting, in vehicle-treated $\mathrm{MDR}+\mathrm{KC}$ grafts at $15 \mathrm{wk}$, in colchicine-treated MDR+KC grafts at $15 \mathrm{wk}$, and in normal human KC.

We compared MDR1 transgene copy number to percentage of $\mathrm{MDR}+\mathrm{KC}$ by using quantitative real-time PCR to determine how many $M D R$ transgenes are present in a defined population of $\mathrm{KC}$. We prepared genomic DNA from colchicine- and vehicle-treated $\mathrm{MDR}+\mathrm{KC}$ grafts, $15 \mathrm{wk}$ after grafting, and determined the relative copy number of the $M D R$ transgene, normalized to the endogenous human hematopoietic cell kinase 1 (HCK) gene (Fig. 4). Compared with the initial MDR $+\mathrm{KC}$ grafts at the time of grafting, the colchicine-treated $\mathrm{MDR}+\mathrm{KC}$ grafts contained a relative $M D R$ copy number of $1.14 \pm 0.41(n=8)$, whereas the vehicle-treated grafts had a significantly lower relative $M D R$ copy number of $0.34 \pm$ $0.16(n=7)(P=0.008)$, an approximate 4-fold increase in the colchicine-treated grafts. These data argue that the 7-fold increase in the percentage of MDR $+\mathrm{KC}$ that occurs with colchicine selection is due, in large part, to selection for increased percentages of $\mathrm{MDR}+\mathrm{KC}$ stem cells. Based on these PCR results, it is still possible that silencing of the $M D R$ gene may account for some of the decrease in MDR $+\mathrm{KC}$ seen in vehicle-treated grafts.

\section{Discussion}

In vivo gene expression of retroviral vector constructs is often lost or diminished over time, hampering the successful application of gene therapy $(35,36)$. Attempts to achieve persistent gene expression at high levels by in vivo selection of hematopoietic cells transduced with selectable genes (dihydrofolate reductase, $O^{6}$-alkylguanine DNA alkyltransferase, cytidine deaminase, $M D R 1$, or MRP1) have had variable success. Although treatment with the appropriate cytotoxic agent led to a significant increase of transduced cells in some instances $(6,8)$, including complete replacement of canine bone marrow by $M D R 1$-transduced hematopoietic cells (12), other reports demonstrated small increases detectable by PCR $(10,11)$. In addition, systemic selection with a cytotoxic drug often results in toxic side effects, sometimes leading to death of treated animals $(6,12)$. As a result, the feasibility of in vivo selection to enrich for genetically modified cells expressing high levels of a desired transgene has been questioned (35).

One tremendous advantage of skin over other tissues is accessibility. Topical selection allows high local concentrations of the selecting agent in the target tissue while minimizing unwanted systemic effects $(37,38)$. Although the percentage of $\mathrm{MDR}+\mathrm{KC}$ in grafts declined over time from an initial $48 \%$ to $13 \%$ and $7 \%$ at 9 and $15 \mathrm{wk}$, respectively, we demonstrate that topical colchicine selection can reverse this decline and significantly increased the percentage of $\mathrm{MDR}+\mathrm{KC}$ to $50 \%$ and $44 \%$, a 7 -fold increase at 15 wk. Even when topical colchicine is initiated 12 wk after grafting (vehicle-treated grafts containing $7-13 \% \mathrm{MDR}+\mathrm{KC}$ ), we could still increase the percentage of $\mathrm{MDR}+\mathrm{KC}$ to $35 \%$ with 12 addi- 
tional weeks of colchicine treatment. These results have important implications for skin gene therapy because they demonstrate that topical selection approaches can successfully achieve significant levels of gene expression in the skin by linking the expression of desired genes to MDR1.

Two different mechanisms, either separately or in combination, may explain how colchicine selection increases the percentage of $\mathrm{MDR}+\mathrm{KC}$ and increases the level of $M D R 1$ expression in individual KC: First, colchicine selection increases the percentage of $\mathrm{KC}$ progenitor cells that contain and express $M D R 1$; second, colchicine selection prevents the silencing of $M D R 1$ expression in $\mathrm{KC}$ containing the MDRl gene $(4,5)$. Our quantitative real-time PCR shows that $\mathrm{KC}$ in colchicine-treated grafts contain 4-fold more $M D R$ transgenes at 15 wk than vehicle-treated grafts and demonstrate colchicine selection increases the percentages of MDR $+\mathrm{KC}$, primarily by expanding the population of $\mathrm{KC}$ progenitor cells that contain the $M D R$ gene. Only KC progenitor cells expressing the P-glycoprotein are able to divide, proliferate, and repopulate the epidermis in the presence of colchicine, whereas $\mathrm{KC}$ progenitors that lack P-glycoprotein will be blocked in mitosis and eventually undergo apoptosis (39). Additionally, the low percentage of $\mathrm{MDR}+\mathrm{KC}$ in vehicle-treated grafts after $15 \mathrm{wk}$ would indicate that only a small percentage of the $\mathrm{KC}$ progenitor cells $(<7 \%)$ were initially transduced with $M D R 1$ during ex vivo culture. In this mechanism, every $\mathrm{KC}$ containing $M D R I$ would be expected to be an MDR $+\mathrm{KC}$, and after many epidermal turnovers, the percentage of $\mathrm{MDR}+\mathrm{KC}$ in the grafts should accurately indicate the percentage of KC progenitor cells that contain MDR1.

It is also possible, but unlikely, that colchicine prevented $M D R 1$ gene silencing, partially contributing to the increase of $\mathrm{MDR}+\mathrm{KC}$ found in colchicine-treated grafts. Our FACS data demonstrating that colchicine treatment significantly increased the level of $\mathrm{P}$-glycoprotein on individual MDR $+\mathrm{KC}$ could be used to argue that topical colchicine can also increase $M D R 1$ expression, consistent with an ability to impede $M D R$ gene silencing. However, a more likely explanation is that colchicine treatment selects for cells that express more Pglycoprotein, as has been demonstrated repeatedly in in vitro cell culture systems $(37,38)$. The finding that colchicine treatment can increase overall $\mathrm{P}$-glycoprotein expression and percentage of $\mathrm{MDR}+\mathrm{KC}$ in grafts, many weeks after transplant when the percentage of positive cells has declined, is consistent with a selective advantage of $\mathrm{MDR}+\mathrm{KC}$ remaining in the population. Another mechanism for the enhanced $M D R 1$ expression per KC may be selection by colchicine for $\mathrm{MDR}+\mathrm{KC}$ containing higher numbers of integrated MDR1 genes. However, a low multiplicity of infection (1-2) was used during ex vivo $\mathrm{KC}$ transduction, and most $\mathrm{MDR}+\mathrm{KC}$ would not be expected to contain multiple $M D R$ copies. Gene amplification of the integrated retroviral $M D R$ genes during colchicine selection would be an unlikely explanation for the increase in $M D R$ copy number detected by quantitative PCR because this has never been observed in vitro (unpublished observations).

Recently, a myeloproliferative syndrome has been reported in mice engrafted with murine hematopoietic cells transduced with the human MDRI vector and selected ex vivo $(40,41)$. High-level MDR1 expression in our human skin grafts did not interfere with the development and maintenance of a differentiated epidermis, and no evidence of neoplasia was present, consistent with other preclinical and clinical studies $(10,11,42-45)$.

Given the problem of persistent in vivo expression of a desired gene at high levels in gene therapy studies $(12,38)$, our approach of topical selection for MDR1 gene expression in KC should make elevated and durable gene expression in the skin a successful reality. However, there still remain important questions to be answered. One is, whether the maximum percentage of $\mathrm{MDR}+\mathrm{KC}$ can be increased to more than the $50 \%$ achieved in this study by optimizing the colchicine dosing schedule and increasing the duration of treatment. Another is what will happen to the percentage $\mathrm{MDR}+\mathrm{KC}$ after long-term colchicine treatment is discontinued. If colchicine has in fact increased the percentage of $\mathrm{KC}$ progenitor cells containing and expressing $M D R 1$, then the percentage of $\mathrm{MDR}+\mathrm{KC}$ should continue to be elevated in the absence of colchicine selection. Based on the results presented here, we anticipate that topical transgene selection holds great promise for future applications in clinical skin gene therapy trials that require significant levels of gene expression in a high percentage of $\mathrm{KC}$.

We thank Dr. Seth Steinberg and Dave Liewehr for valuable statistical advice in both the design and analysis of these experiments; Drs. Mark Udey, Stephen Katz, and Kim Yancey for valuable critical advice and suggestions; Mohamed Joari for cell culture assistance; Dr. Ariana Huber for advice on quantitative real-time PCR; and Organogensis for help with experimental reagents and materials.
1. Fenjves, E., Yao, S.-N., Kurachi, K. \& Taichman, L. (1996) J. Invest. Dermatol. 106, 576-578 2. Choate, K. \& Khavari, P. (1997) Hum. Gene Ther. 8, 895-901.

3. White, S., Page, S., Margaritis, P. \& Brownlee, G. (1998) Hum. Gene Ther. 9, 1187-1195.

4. Chen, W., Bailey, E., McCune, S., Dong, J. \& Townes, T. (1997) Proc. Natl. Acad. Sci. USA 94, 5798-5803.

5. Bestor, T. H. (2000) J. Clin. Invest. 105, 409-411.

6. Allay, J. A., Persons, D. A., Galipeau, J., Riberdy, J. M., Ashmun, R. A., Blakley, R. L. \& Sorrentino, B. P. (1998) Nat. Med. 4, 1136-1143.

7. Zhao, S. C., Li, M. X., Banerjee, D., Schweitzer, B. I., Mineishi, S., Gilboa, E. \& Bertino, J. R. (1994) Cancer Gene Ther. 1, 27-33.

8. Sawai, N., Zhou, S., Vanin, E. F., Houghton, P., Brent, T. P. \& Sorrentino, B. P. (2001) Mol. Ther 3, 78-87.

9. Ragg, S., Xu-Welliver, M., Bailey, J., D’Souza, M., Cooper, R., Chandra, S., Seshadri, R., Pegg, A. E. \& Williams, D. A. (2000) Cancer Res. 60, 5187-5195.

10. Podda, S., Ward, M., Himelstein, A., Richardson, C., Flor-Weiss, E. D. L., Smith, L., Gottesman, M., Pastan, I. \& Bank, A. (1992) Proc. Natl. Acad. Sci. USA 89, 9676-9680.

11. Sorrentino, B., Brandt, S., Bodine, D., Gottesman, M., Pastan, I., Cline, A. \& Nienhuis, A. (1992) Science 257, 99-103.

12. Licht, T., Haskins, M., Henthorn, P., Kleiman, S. E., Bodine, D. E., Whitwam, T., Puck, J. M., Gottesman, M. M. \& Melniczek, J. R. (2002) Proc. Natl. Acad. Sci. USA 99, 3123-3128.

3. Pfutzner, W. \& Vogel, J. C. (2000) Exp. Opin. Invest. Drugs 9, 2069-2083.

14. Taichman, L. (1994) in The Keratinocyte Handbook, eds. Leigh, I., Lane, E. \& Watt, F. Taichman, L. (1994) in The Keratinocyte Handbook, e
(Cambridge Univ. Press, Cambridge, U.K.), pp. 543-551.

Khavari, P. A. (1997) Mol. Med. Today 3, 533-538.

16. Choate, K., Medalie, D., Morgan, J. \& Khavari, P. (1996) Nat. Med. 2, 1263-1267.

17. Kolodka, T., Garlick, J. \& Taichman, L. (1998) Proc. Natl. Acad. Sci. USA 95, 4356-4361.

18. Uitto, J. \& Pulkkinen, L. (2000) Hum. Gene Ther. 11, 2267-2275.

19. Khavari, P. A. (1998) J. Invest. Dermatol. 110, 462-467.

20. Taichman, L. B. (1999) Proc. Assoc. Am. Physicians 111, 206-210.

21. Morgan, J., Barrandon, Y., Green, H. \& Mulligan, R. (1987) Science 237, 1476-1479.

22. Levy, L., Broad, S., Zhu, A., Carroll, J., Khazaal, I., Peault, B. \& Watt, F. (1998) Gene Ther. 5, 913-922.

23. Deng, H., Lin, Q. \& Khavari, P. (1997) Nat. Biotechnol. 15, 1388-1391.

24. Gerrard, A., Hudson, D., Brownlee, G. \& Watt, F. (1993) Nat. Genet. 3, 180-183.
25. Pfutzner, W., Hengge, U. R., Joari, M. A., Foster, R. A. \& Vogel, J. C. (1999) Hum. Gene Ther. 10, 2811-2821.

26. Gottesman, M. \& Pastan, I. (1993) Annu. Rev. Biochem. 62, 385-427.

27. Higgins, C. (1993) Curr. Opin. Cell Biol. 5, 684-687.

28. Cordon-Cardo, C., O’Brien, J., Boccia, J., Casals, D., Bertino, J. \& Melamed, M. (1990) J. Histochem. Cytochem. 38, 1277-1287.

29. Thiebaut, F., Tsuruo, T., Hamada, H., Gottesman, M., Pastan, I. \& Willingham, M. (1987) Proc. Natl. Acad. Sci. USA 84, 7735-7738.

30. Pastan, I., Gottesman, M., Ueda, K., Lovelace, E., Rutherford, A. \& Willingham, M. (1988) Proc. Natl. Acad. Sci. USA 85, 4486-4490.

31. Garlick, J. A. \& Taichman, L. B. (1994) Lab. Invest. 70, 916-924.

32. Gelfant, S. (1982) J. Invest. Dermatol. 78, 296-299.

33. Halprin, K. (1972) Br. J. Dermatol. 86, 14-19.

44. Morris, R. J., Fischer, S. M. \& Slaga, T. J. (1985) J. Invest. Dermatol. 84, 277-281.

5. Brenner, M. (1999) Gene Ther. 6, 1646-1647.

36. Palmer, T., Rosman, G., Osborne, W. \& Miller, A. (1991) Proc. Natl. Acad. Sci. USA 88, 1330-1334.

37. Licht, T., Herrmann, F., Gottesman, M. M. \& Pastan, I. (1997) Stem Cells (Dayton) 15, 104-111.

38. Gottesman, M. M., Licht, T., Zhou, Y., Lee, C., Shoshani-Kupitz, T., Hafkemeyer, P., Hrycyna, C. A. \& Pastan, I. (2000) in Gene Therapy: Therapeutic Mechanisms and Strategies, eds. Templeton, N. S. \& Lasic, D. (Dekker, New York), pp. 333-352.

39. Tsukidate, K., Yamamoto, K., Snyder, J. \& Farber, J. (1993) Am. J. Pathol. 143, 918-925.

40. Bunting, K., Galipeau, J., Topham, D., Benaim, E. \& Sorrentino, B. (1998) Blood 92 2269-2279.

41. Bunting, K. D., Zhou, S., Lu, T. \& Sorrentino, B. P. (2000) Blood 96, 902-909.

42. Hanania, E., Giles, R., Kavanagh, J., Fu, S., Ellerson, D., Zu, Z., Wang, T., Su, Y., Kudelka, A., Rahman, Z., et al. (1996) Proc. Natl. Acad. Sci. USA 93, 15346-15351.

43. Hesdorffer, C., Ayello, J., Ward, M., Kaubisch, A., Vahdat, L., Balmaceda, C., Garrett, T., Fetell, M., Reiss, R., Bank, A., et al. (1998) J. Clin. Oncol. 16, 165-172.

44. Mickisch, G. H., Pai, L. H., Gottesman, M. M. \& Pastan, I. (1992) Cancer Res. 52, $4427-4432$.

45. Moscow, J., Huang, H., Carter, C., Hines, K., Zujewski, J., Cusack, G., Chow, C., Venzon, D., Sorrentino, B., Chiang, Y., et al. (1999) Blood 94, 52-61. 